\title{
Physicochemical characterization of PEEK coated by SPEEK films for Implant Dentistry applications.
}

Kurihara, R; Brum, RS; Nobre, PC; Guzi, E; Novaes, AP; Volpato CAM; Benfatti, CAM

\section{Abstract}

Biocompatible poly-ether-ether-ketone (PEEK) has emerged as a possible alternative to titanium implants (1). It is already being used as healing screws and provisional abutments $(2,3)$. To overcome its lack of bioactivity, to reach anti-biofilm properties and to improve its mechanical properties, some strategies have been proposed. Among them, the development of a PEEK- based composite with natural amorphous silica fibers (NASF) (4) and the employment of sulfonated-PEEK (SPEEK) films are promising approaches (5). The aim of the present study was to produce and to evaluate the physicochemical and topographical properties of PEEK, NASF and PEEK/NASF samples, coated by sulfonated PEEK (SPEEK) for implant dentistry applications. PEEK (Invibio®, Batch: D0602, grau: NI1) was manufactured by compression molding (PEEK, $\mathrm{N}=18$ ). To produce PEEK/NASF samples, $0.5 \mathrm{~g}$ of anhydrous citric acid (Synth, Brazil) was added into isopropyl alcohol (PEEK/NASF, N=18). NASF samples were prepared using $5 \%$ of bentonite in aqueous medium (NASF, $N=18$ ). All samples were manufactured in a steel mold of $5,5 \mathrm{~mm} \times 10 \mathrm{~mm}$ and treated thermally for 30 minutes (300-350 o C). Biomedical grade PEEK was functionalized using sulfuric acid $98 \%$ (Synth $\Theta$, Brasil). A sonic dismembrator (Misonix - Sonicator 4000, USA) was used to obtain a homogeneous solution of SPEEK/DMSO. Half of samples of PEEK, PEEK/NASF and NASF were dip coated with SPEEK/DMSO films (PEEK-S, N=9; PEEK/NASF-S, N=9, NASF-S, N=9). Physicochemical characterization was realized through Fourier Transformed Infrared (FTIR) spectroscopy, while topographical analysis was evaluated through surface roughness, contact angle and scanning electron microscopy (SEM). FTIR spectrum showed characteristic bands of PEEK (925 cm -1, $1158 \mathrm{~cm} \mathrm{-1,1594} \mathrm{cm} \mathrm{-1,1650} \mathrm{cm} \mathrm{-1),} \mathrm{silica} \mathrm{fibers}$ $(790 \mathrm{~cm} \mathrm{-1)}$, citric acid $(1752 \mathrm{~cm} \mathrm{-1)}$ and sulfonic groups $(1010 \mathrm{~cm} \mathrm{-1,1090} \mathrm{cm} \mathrm{-1)} \mathrm{according} \mathrm{to} \mathrm{the} \mathrm{kind}$ of sample and treatment employed. PEEK/NASF-S samples showed the highest Ra value (mean 5.441), statistically different from the other groups (PEEK: 1.304, NASF: 1.45, PEEK/NASF: 4.38, PEEK-S;1.30, NASF-S:1.06). Contact angle measurements varied between 82.66 and 90.5 angles between PEEK, PEEK-S, PEEK/NASF and PEEK/NASF-S and did not show statistical difference among each other. NASF contact angle could not be obtained since samples absorbed water instantly. SEM images evidenced superficial differences among groups. Silica fibers were found in PEEK/NASF, NASF, PEEK/NASF-S and NASF-S. No substantial differences were found between NASF and NASF-S samples, while PEEK/NASF and PEEK samples showed a more homogeneous surface when compared to PEEK/NASF-S and PEEK-S samples. Interesting topographical and physicochemical properties were obtained through the production of PEEK/NASF composites and its treatment with sulfonated-PEEK films. Comprehensive biological assays are needed in order to evaluate whether this approach is promising to improve PEEK bioactivity and anti-biofilm properties. In the event of promising results, periimplant diseases could eventually be prevented and treated.

\section{Results}
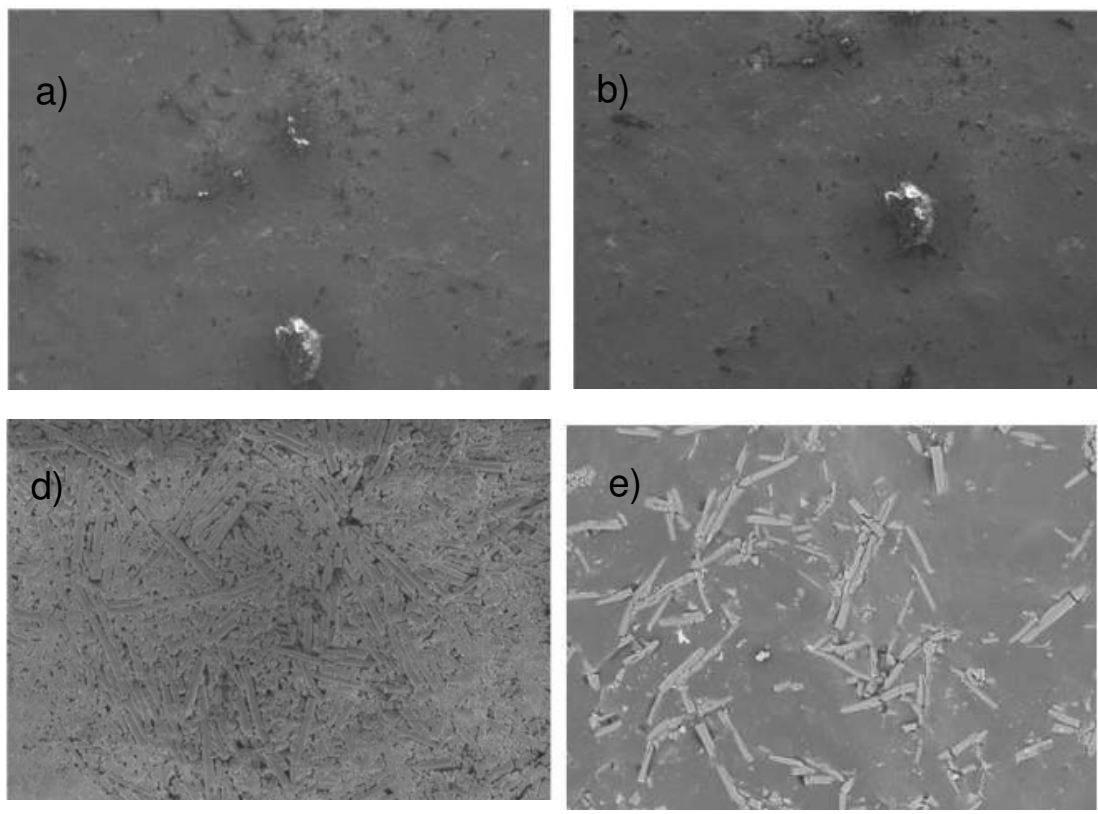

Fig. 1: SEM images of a) PEEK; b) PEEK-S; c) NASF; d) NASF-S; e) PEEK/NASF; f) PEEK/NASF-S;

Fig. 2: Ra values from righ to left bars: PEEK; PEEK-S; NASF; NASF-S; PEEK/NASF and PEEK/NASF-S $(P<0.05)$
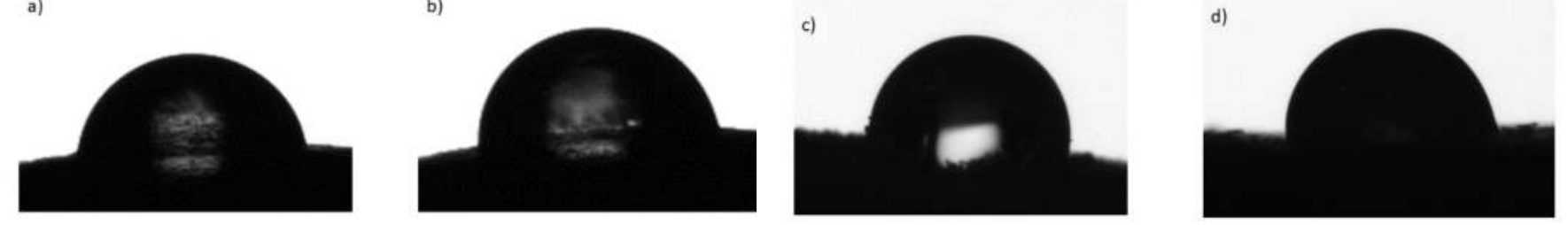

Fig. 3: Contact angle images of a) PEEK; b) PEEK-S and c) PEEK/NASF and d) PEEK/NASF-S $(P>0.05)$

\section{Background and Aim}

\section{Conclusion}

Biocompatible poly-ether-ether-ketone (PEEK) has emerged as a possible alternative to titanium implants. It is already being used as healing screws and provisional abutments. To overcome its lack of bioactivity, to reach anti-biofilm properties and to improve its mechanical properties, some strategies have been proposed. Among them, the development of a PEEK- based composite with natural amorphous silica fibers (NASF) and the employment of sulfonated-PEEK (SPEEK) films are promising approaches. The aim of the present study was to produce and to evaluate the physicochemical and topographical properties of PEEK, NASF and PEEK/NASF samples, coated by sulfonated PEEK (SPEEK) for implant dentistry applications.

\section{Methods and Materials}

PEEK (Invibio ${ }^{\circledR}$, Batch: D0602, grau: N11) was manufactured by compression molding (PEEK, N=18). To produce PEEK/NASF samples, $0.5 \mathrm{~g}$ of anhydrous citric acid (Synth, Brazil) was added into isopropyl alcohol (PEEK/NASF, N=18). NASF samples were prepared using $5 \%$ of bentonite in aqueous medium (NASF, $\mathrm{N}=18$ ). All samples were manufactured in a steel mold of $5,5 \mathrm{~mm} \times 10 \mathrm{~mm}$ and treated thermally for 30 minutes (300-350 o C). Biomedical grade PEEK was functionalized using sulfuric acid $98 \%$ (Synth $\circledast$, Brasil). A sonic dismembrator (Misonix - Sonicator 4000, USA) was used to obtain a homogeneous solution of SPEEK/DMSO. Half of samples of PEEK, PEEK/NASF and NASF were dip coated with SPEEK/DMSO films (PEEK-S, N=9; PEEK/NASF-S, N=9, NASF-S, N=9). Physicochemical characterization was realized through Fourier Transformed Infrared (FTIR) spectroscopy, while topographical analysis was evaluated through surface roughness, contact angle and scanning electron microscopy (SEM).
Interesting topographical and physicochemical properties were obtained through the production of PEEK/NASF composites and its treatment with sulfonated-PEEK films. Comprehensive biological assays are needed in order to evaluate whether this approach is promising to improve PEEK bioactivity and anti-biofilm properties. In the event of promising results, peri-implant diseases could eventually be prevented and treated.
1) KURTZ, S. M.; DEVINE, J. N. PEEK biomaterials in trauma, orthopedic, and spinal implants. Biomaterials 2007; 28(32):4845-69.

2) SCHWITALLA, A.; MULLER, W. D. PEEK dental implants: a review of the literature. J Oral Implantol 2013; 39(6):743-9

3) AGUSTÍN-PANADERO, R. et al. Mechanical behavior of provisional implant prosthetic abutments Med Oral Patol Oral Cir Bucal 2015; 20(1):e94-102.

4) Monich PR et al. Physicochemical and biological assessment of PEEK composites embedding natural amorphous silica fibers for biomedical applications. Mater Sci Eng C Mater Biol Appl. 2017 Oct 1;79:354-362. doi: 10.1016/j.msec.2017.05.031. Epub 2017 May 8.

5) MONTERO, J. F. et al. Chemical, microscopic, and microbiological analysis of a functionalized polyether-ether-ketone-embedding antibiofilm compounds. J Biomed Mater Res A 2016; 104(12):3015- 